\title{
The Sociology of Gender Equality and Development in Democratizing Nigeria
}

\author{
Olayinka Akanle \\ Department of Sociology \\ Faculty of the Social Sciences \\ University of Ibadan, Nigeria
}

DOI: $10.36108 / \mathrm{NJSA} / 1102 / 90(0110)$

Vol. 9 Issue 1, 2011

\begin{abstract}
Although it is commonly believed that gender equality is a human right issue and that its protection should be natural and non-negotiable, this is usually not the case especially in Africa with deep-rooted traditional systems and patriarchal structures that sustain gender inequality. Since Nigeria's return to democracy, even against the backdrop of huge militarization of the psyche of Nigerians due to long spell with military dictatorship, it would be expected that the gender landscape of the country should have of necessity improved. Somewhat, democracy has influenced gender relations relative to equality and the legal environment, but translating this to development remains critically questionable. While involvement of women in politics has become more visible, as more women now hold political offices and the law is more gender sensitive, the real preponderance of the intermingling of gender equality, justice system, political dynamics and development outcomes in Nigeria, however, remains clumsy and necessitates fresh interrogation. This paper, therefore, examines the nexus of gender equality and development against legal trajectories within Nigeria's democratizing realities.
\end{abstract}

Keywords: gender equality, rule of law, sustainable development, Nigeria

\section{Introduction}

Regardless of the prevailing political and justice systems, no society can develop without objective gender equality because it is impossible for anyone to clap with one hand, and no bird can fly with one wing.

Against the background of the above quotation, it is not surprising that the American Bar Association Rule of Law Initiative maintained that lack of gender equality is a major stumbling block to rule of law, personal wellbeing, and development around the globe, and that societies with greater gender inequality face higher incidence of poverty, malnutrition, ill-health, lower educational attainment, slower growth and weaker governance. It is therefore important for any society or nation pursuing development, especially sustainable one, to be concerned with gender equality and rule of law. This has been well recognized by scholars down the ages. Melander (2005), for instance, established a strong link between gender equality and preponderance of human rights abuse, submitting that once there is greater political equality, 

this will impact the nature of abuse and the capacity to prevent and seek redress which could ultimately influence the process of development. La Vaque-Manty and La Vaque-Manty (2006) also echoed the importance of gender dynamics in dignity and implications for political inclusiveness even in somewhat traditional political systems and aristocracy.

For Joireman (2001), the historiography of the justice systems and legal domains are equally important for gender equality in any political system especially within the context of African colonial legacy, with inherited legal systems and implications for the effectiveness of rule of law. According to Ganguly-Scrase (2003), contemporary realities like democracy (see also Rizzo, Abdel-Latif and Meyer, 2007), gender equality, globalization and even liberalization may also present paradoxes and must therefore not be taken for granted in their intermingling and consequences. As against the usual expectation of many activists, recent happenings like democracy may not necessarily bring gender equality and development and their manifestations and contours must be well comprehended if they are to have real and desired development effects in the final analysis. This is why questions bothering on gender equality must constantly be engaged especially as structures of government and justice environments change. It is therefore impossible and fool-hardy to rule out gender equality (Nyamu-Musembi, 2006) and rule of law as developing nations struggle for development even in political transitions and as democracy gain ascendancy since complementary gender relations (Gray and Neill, 2011; Hamer and Hamer, 1994) could have positive developmental values.

Without necessary gender equality with appropriate rule of law orientation and practices, what any nation will have will be nothing but what Leve (2007) referred to as failed development regardless of the professed degree of women empowerment as was the case in Nepal. Right from language use to affirmative actions, no gender should be kept hostage, and governance structures and legal regimes must have liberating effects if they are to lead to and sustain development. This liberating activism has already crystallized in Europe and this was well documented with respect to Poland, for instance, by Platek (2004) when women rejected the phrase husband of trust label and description even when they play enviable leadership role. As already discovered by Sociologists, as underscored by Risman (2004) in the classic Gender as a Social Structure: Theory Wrestling with Activism, gender is intricately intertwined in the culture of people, is often justified, perpetrated and perpetuated through the culture, norms and values that are strongly enduring. They are resilient and beneficial to some class who would struggle to maintain the status quo.

People who benefit from being on top the others will thus prefer to hold on to the existing pattern and struggle to continue to predominate even against common will and interest as codified in the necessity of development. The 
popular participation that endears many to democracy, particular justice systems as codified in rule of law and the drive for gender equality must, therefore, be galvanized positively if development will be possible in the $21^{\text {st }}$ century Nigeria, and beyond, with the hurricane of democracy sweeping across the world as already being witnessed through the Arab Spring Uprising. Unfortunately, these trajectories of gender equality, rule of law and democracy have not been optimized and well galvanized in Nigeria even as the nation consolidates its democracy and anticipates development. Democratic dividends are yet to be seen and felt in real terms to suggest the nation is on the right track to sustainable development. Largely, development in Nigeria could be best said to be retrogressing regrettably. A consideration of Nigeria's development terrain is thus necessary.

\section{The Nigeria's Development Domains}

Nigeria is usually referred to as the giant of Africa because of its numerical strength, involvement in foreign military operations and huge natural resources. The British Broadcasting Corporation (BBC) Online data base ${ }^{1}$ however referred to Nigeria as a troubled giant. This will become clearer heretofore. Nigeria is Africa's most populous nation and among the biggest in the world. Nigeria has a land area of 923, 768 square $\mathrm{km}(356,667$ square miles) with good landscape for agricultural and commercial activities. It is the sixth largest producer of crude oil in the world and the biggest oil exporter in Africa with the largest natural gas reserves in the continent. The nation also has the largest human reserve which should ordinarily propel development.

Nigerian's population is about 140 million (Federal Government of Nigeria, 2007) and about half of this population are capable people willing to work. Nigeria is close to 20 percent of Sub-Saharan Africa, 47 percent of West Africa and is the sub-continent's second largest economy (World Bank, 2003; Federal Government of Nigeria, 2007). Nigeria became independent in 1960, had over 30 years spell with military rule, only re-democratized in 1999 and witnessed civil war in 1967-1970. Nigeria is one of the poorest countries in the world with poverty burden of over 70 percent by less than $\$ 1$ a day measure (Federal Ministry of Women Affairs and Social Development, 2007) and 90 percent by less than $\$ 2$ a day measure. Nigeria has political instability, widespread post-election violence greeted the 2007 general elections in Nigeria as was the case in previous elections. Even today, there are widespread ethnoreligious differences and militancy that is sustained and recently crystallized in terrorism and sectionalism that is now popularly known as Boko Haram. Boko Haram terrorists have killed hundreds of people especially in Northern Nigeria and the killing still continues as the security agents have failed in their effort to combat terrorism.

\footnotetext{
${ }^{1}$ Nigeria Profile http://www.bbc.co.uk/news/world-africa-13949550. Accessed on 16th March, 2012
} 
Boko Haram is said to have links with Al-Qaida and President Goodluck Jonathan of Nigeria has publicly declared that Boko Haram has infiltrated his government. That was a public declaration of helplessness from the highest political office holder in the country, the Commander-in-Chief of the Armed Forces, and the highest sign of authority in the nation. Nigeria is ranked among the most corrupt nations in the world and mismanagement has undermined Nigerian development in many ways. Investment climates in the country are usually considered unstable even as already established industries now relocate to neighboring Ghana and beyond and past military and civil leaders have not been able to diversify the economy ${ }^{2}$. This has negatively affected development and the political legitimacy of political rulers in the country.

Although Nigeria experienced economic growth rate of about 7.6 percent between 2003 and 2010, this has rescinded, and even the one recorded in 20032010 did not translate to any positive sustainable development as poverty remains(ed) either constant or increased. Unemployment rate in Nigeria is about 21 percent, GDP (purchasing power is $\$ 414.5$ billion with GDP real growth rate of less than 7 percent, GDP per capita is $\$ 2,600$ with labour force of 51.53 million (see CIA The World Fact Book, 2012 ${ }^{3}$ ). There are infant and maternal mortality and morbidity overloads in Nigeria. One in 5 children dies before age 5 and HIV/AIDS poses a threat to the nation.

Due to the core interaction of local capacities and global demand for food and overall agricultural system (Von Braun, 2008), national inflation rate stands at record high oscillating around 15 percent, and the nation ranks poorly on all development indicators of the Human Development Index (HDI) including; participation in education, health, employment and political participation (World Development Report (2012) ${ }^{4}$. Unfortunately, while Nigeria remains a major consumer of agricultural products in the world, it has not been able to engage in desperate efforts to salvage its agricultural systems like those attempted in Zimbabwe. This is largely due to its fixation at the level of mono-product economy displayed in over-dependence on oil as the main source of foreign exchange earnings. Over 90 percent of Nigeria's foreign exchange earning to day comes from crude oil export as against the situation in the pre-oil 1960s when agriculture employed over 70 percent of Nigerians and earned most of the foreign exchange for the nation. The arable land is still there and the manpower is still available. What has changed negatively is the political will and capacity even when technology has improved.

\footnotetext{
${ }^{2}$ Crude oil still account for 95 percent of Nigeria's foreign earnings and 80 percent of budgetary revenue

${ }^{3}$ Available at https://www.cia.gov/library/publications/the-worldfactbook/geos/ni.html. Accessed 17/03/2012.
} 
On the achievement of the Millennium Development Goals (MDGS), Nigeria is said to be off-track on most of the critical indicators and goals (Yumkella, 2008). A minimum of 10 million Nigerian children are out of school and at least 15 million engage in hazardous child labour due to poverty (United Nations Children Emergency Fund, 2005). The nation is also in a gender crisis as patriarchy holds sway with the critical social institutions being male dominated, stifling necessary contribution of the female folks. As Nigeria struggles to cope with its development challenges, critical missing links are observable in terms of development efforts in the nation. This is particularly so relative to gender and rule of law within democratic institutionalization and context. The time has thus come for the Sociology of Law and/or Sociology of Legal Studies, as well as Sociology of Development and/or Development Studies to be more proactive and deploy needed critical analytical tools to engage issues central to this article. This article therefore annexed the strengths and veritable tools of Sociology of Law, Gender Studies, Political Sociology and Sociology of Development to engage the problematique in pragmatic manner to positively affect academic scholarship and practical government for driving sustainable development in Nigeria.

\section{Sex, Gender and Rule of Law: What do they mean?}

Sex is natural and biological. It is the biological characteristics which define humans as males or female depending on the nature and types of physical attributes possessed by the person or people in question. Sex is thus naturally given and constructed. Moreover, sex is uniform across the world. A male in Nigeria is one in the United States and a female in China is one in Ghana. This does not vary across board and society unlike gender. Unlike gender constructs of relations that could described as unfair, sex is fair as it is naturally bestowed. It is harmless and only become harmful when and once translated to gender and roles are socially allocated based on sex and associated characteristics. Unlike gender, sex is beyond choice.

Gender, on the other hand, refers to the socially and culturally constructed roles of, and relation, between men and women. This unfortunately has led to patriarchy, a system where every social situation, real or imagined, are viewed and assessed in masculinity. Roles and expectations towards the ideal and the expected and the taken are viewed as given in favour of the males. This is not based on the merit of capacities of the individuals or groups involved but based on gender ascriptions by society. This is common in all developing societies especially sub-Saharan Africa and Asia. It is important to note, however, that gender is artificial, unfair, and its nature as well as degree of adoption varies across societies. Also, gender is a learned behaviour.

People learn gender role play and judgment through socialization processes that pre-date them, but sex is not and people meet and are forced to accept their sex naturally. Right from the first point of socialization at the family level, people are socialized into gender elements from the first day they begin to learn societal ethos. Adoption of such ethos is reinforced while deviation is 
sanctioned. Once socialization is successful, the ethos become internalized and very difficult, if not impossible, to jettison as the member of society/person involved must have become eja gbigbe (someone beyond control) with impressions and attitudes already formed. This becomes more problematic if such primordial role allocations and dichotomized allocation favours the person(s) involved. Unfortunately such favourable circumstances do not have direct relationships with gender itself. In other words, such allocations could even favour a female, and this is more so in the $21^{\text {st }}$ century Nigeria where more roles are becoming feminized. This has forced many to begin to question orthodox gender arguments and to advocate the need for a shift to consider gender discrimination against men particularly in the economic system.

Across all institutions, gender relations are characterized by unequal power as already allocated by the social systems about which individual choices are also limited. Gender norms allocate specific tasks, roles and entitlement and responsibilities to male and female. For instance, women might be expected to take on caring or domestic duties and remain close to the home, while men may be expected to work outdoors and be as the breadwinner with greater freedom to move around in public places and occupy roles that are elastic. Gender roles attract benefits and expectations, and choices that are made are given but bound by norms and values. Any gender that goes beyond bounds could be sanctioned in many ways - the most common being ostracism and labelling. Regardless of many discussions and advocacies across time and domains, gender inequality and its negative outcomes persists, with implications for capacities to benefit from global/national trade and development policies. This is regardless of the fact that gender is considered important and central to human development. This has led to the emergence and rise of Gender Equality as a concept and movement.

It is not easy to define rule of law. In fact, there are many definitions for the concept and principle. Succinctly put, however, according to A.V. Dicey in 1885, in his classic An Introduction to the Study of the Law of the Constitution, Rule of Law is the absolute supremacy of the law or predominance of regular law and equality before the law. According to Azinge (2009), basic elements of rule of law are: the supremacy of rule of law above arbitrary powers, the equality of all before the law, government under the law, the belief that there is nothing higher than the rights of individuals as determined by the courts. By this, it means no single individual regardless of economic and social status is beyond the law. Whether a man or woman, everyone should be equal before the law. The law is not, and should not, be partial relative to any subjective element. This is why it is often said that the law is blind or should be blind. Basic characteristics of rule of law are: equality before the law, general clarity of the law, transparent process accessible to all, prohibition of cruel and degrading treatment, free legal climate devoid of segregation. 


\section{Gender Equality, Rule of Law and Development Relationships in Nigeria}

Gender equality is, sometimes, synonymous with gender equity, gender egalitarianism or sexual equality. Gender equality is the goal of the equality of the genders or the sexes stemming from a belief in the injustice of myriad forms of gender equality. World bodies have also defined gender equality as related to human rights, especially women's rights, and development. According to United Nations Children Fund (UNICEF) gender equality is levelling the playing field for girls and women by ensuring that all children have equal opportunity to develop their talents. Hence, according to United Nations Population Fund (UNFPA), gender equality is first and foremost, a human right. Gender equality does not mean favouring women or being sentimental towards them to pitifully give women what they do not deserve. It is creating and giving opportunities to the two genders to objectively aspire to be the best without socio-cultural and systemic issues debarring one as against another. Gender equality is removing both genders from the shackles of primordial customs and traditions to face the challenges of the $21^{\text {st }}$ century and the information/knowledge age constructively with traditional burden and overloads.

Gender equity is one of the goals of the United Nations Millennium Project, to end world poverty by 2015 . The project claims that, every single goal is directly related to women's rights, and societies where women are not afforded equal rights as men can never achieve development in a sustainable manner. It is, however, important to note that every one of the 8 Millennium Development Goals is also related to men's rights and if the rights of men are compromised the MDGs become unachievable. The rights of one must not be traded off for the protection and realization of the other. Therefore, in promoting gender equality, pariah must not be built between the two genders as is often the case. Although promotion of gender equality could be seen as an encouragement to greater prosperity and development, both genders must be carried along if this is to be a reality. Unfortunately, this has not been the case in Nigeria for a long time and this could account for why gender equality drives in Nigeria have had so much motion without movement, while the problem persists across social institutions and national systems.

A look at the Nigerian Gender Profile will be instructive: ${ }^{5}$ Nigeria is Africa's most populous country, and has great ethnic, cultural and religious diversities, all laced with recipe for gender maligning and discriminations. About 50 percent of Nigerians are women (see the Nigeria Demographic and Health Survey (NDHS) 2003 and 2008 for the details of data presented in this section). The Growth Rate of men is 4.0 percent while that of women is 3.57 percent. As far back as 2006, female literacy rate in Nigeria was 56.8 percent while that of male was 74.7 percent, with overall national rate of 65.7 percent. This is supported by traditional practices that favour male education against

\footnotetext{
${ }^{5}$ Please see the Summary of Nigeria Gender Profile http://siteresources.worldbank.org/EXTAFRREGTOPGENDER/ Resources/nigeria.pdf. accessed 1st July 2011
} 
female. Many cultures in Nigeria consider money spent on female education as a waste since the girl will eventually marry out in the exogamous marriage system, and become the husband's gain as she is culturally expected to bear the husband's name.

On employment, which is the key to actual empowerment, men comprise 68.7 percent of total of Federal Civil Service ${ }^{6}$ in 2006; and women form only 31.3 percent. In the Federal Ministries, women are 32.4 percent, men are 67.6 percent. If disaggregated by teachers in employment, since it is even taken that more women prefer teaching as coping strategy for the double work load, in Primary Schools, women form 50.8 percent of the teachers, and men are 49.2 percent. This is the very first contact and basic education with the least certification necessary. This shall be clearer when tertiary is considered. Even at that the margin of difference is minute. In the Secondary Schools, women comprise 39 percent of the teachers, and men are 61 percent. The margin becomes wider as time factor in certification become more demanding. In tertiary institutions, women are only 18 percent and men are 82 percent. Now the difference is clear as more expertise, energy and time investment in education become more demanding.

By access to bank facilities (loan), women are only 21.9 percent and men are 78.1 percent. This could be explained through cultural necessities that supports bank loan and project finance. Once a woman applies for loan, she is expected to be supported by a husband without whom she is considered irresponsible. Also, collaterals often requested are landed properties and many women do not have access to this. As percentage of trafficked victims, women are 82.4 percent, men are 17.6 percent. More women are trafficked to be used as domestic workers and in most cases prostitutes both locally and internationally.

As percentage of prison inmates, women are 4.5 percent and men are 95.6 percent. Overwhelming proportions of prison inmates are men, showing men are more criminals and crime inclined. Yet, they occupy the most sensitive positions of authority while women are very few in such positions as men dominate the political landscape. Even the 35 percent affirmative action is still a mirage as women appear to be beggars seeking for help from their male counterparts. Between 60 and 90 percent of women still experience Female Genital Mutilation and this is common even at the urban centres. Although the 1999 constitution of the Federal Republic of Nigeria prohibits discrimination on the grounds of gender, customary and religious laws continue to restrict women's rights.

Even the Nigerian Penal Code systematically condones violence against women as what constitute grievous hurt in domestic violence, for instance, remains abysmally unacceptable. For instance, grievous hurt in the Nigerian Penal Code is when a spouse suffers tooth loss and loss of an eye. These degrees

\footnotetext{
${ }^{6}$ This is largest and the most stable employer of labour in Nigeria
} 
of grievous hurt are even very difficult to justice. Even when many women suffer this they do not report to the law for fear of been persecuted in the family institution which is very basic to African social relation and existence. The Penal Code thus grants husbands permission to beat their wives, provided the violence or discipline does not result in serious injury. Unfortunately and regrettably, many women have come to accept this violence and discipline as normal as many have come to see such violence as acceptable to put wives in check. This is why Intimate Partners' Violence (IPV) and domestic violence generally is common especially in polygamous families and affects at least onefifth of couples. The combination of federation and a tripartite system of civil, customary and religious laws thus makes it very difficult to harmonize legislations and remove discriminatory measures by/of genders.

There is also establishment of religious practices that allow and encourage gender discrimination. Roles and status in religious institutions and homes as well as even offices are guided, overtly or covertly, by religious considerations. Although some States have laws that prohibit discrimination against women, especially in cultural practices terms, such laws are however very difficult, if not impossible, to implement due to patriarchy and obnoxious cultural establishments already instituted to protect the status quo. Even within the law, the family and in the social system generally, Nigerian women are not sufficiently protected as already demonstrated above in the case of the Penal Code. An important flip side of the compromised legal systems and regimes is the lacing of law codification and implementation with cultural recipes and flavours. Laws are cultural creations and their implementations can never be divorced from the orthodox cultural systems as humans and Nigerians in particular relate within primordial social webs even in post-modern age. Principles and proverbs like a kiti kootu de sore (we cannot come back from court and ever be friends) explain the critical interface of legal systems and justiceability of gender equality and generalized human rights protection with huge implications for national development. If it is so difficult among friends, how much more among spouses, and in inter-gender relations and law, especially when one party is already systematically disempowered through culture, traditions and modernity.

Several inequalities remain established and are sustained by culture and traditions. Customary law seldom recognises women's rights to inheritance. In many instances, the family of a deceased husband will claim rights to the couple's property, leaving the widow and the children destitute. Nigerian women have very limited ownership rights. Civil law entitles women to have access to land, but certain customary laws stipulate that only men have the right to own land and these extant laws still subsists. Women's access to justice is limited through permission necessity and cultural prohibition. In daily life in Nigeria, men generally make all decisions regarding property. The political environments are also prohibitive of women given the ascendancy of violence and politically motivated assassination. Political offices that are very conspicuous are also seen as exclusive preserve of men. 
Women in Abuja are often seen as prostitutes and irresponsible for abandoning their homes and families for politics supposedly meant for men political gladiators who are culturally expected and permitted to be away on such voyages. This circumscribes the freedom of movement of the endangered gender and limits their right to participation as permitted by the 1999 Constitution of the Federal Republic of Nigeria. It is common knowledge today that political appointments and elections are dominated by men. Political parties do not favour women as their flag bearers in elections as they are often seen as bad candidates that may not be voted for in strongly traditional Nigeria that is extremely patriarchal and sentimental against women. Interestingly, while men do this, women themselves are also their own enemies. Many women do not vote for women as they either envy the politically conscious and active ones or, wrongly, perceive them as irresponsible or deviants. This is however due to the success of the socialization process they have been exposed to from childhood. They have internalized gender discriminating ethos and values in the patriarchal African systems that favour men as against women in exploring such domains. This is thus a double tragedy that makes the issues at stake complex and challenging to be engaged.

The implications of the above trajectories for development in Nigeria are very important. This is because development is only built on the tripod of equality, equity and fairness. It is only in a society where this tripod exists that development can thrive. Laws and the social structural systems must be supported by the tripod and they must support the tripod; otherwise development will always be elusive and remain a mirage since the society will ultimately be seen as unjust and devoid of justice. Once justice is not guaranteed, development becomes impossible. This is because the law is supposed to be the arbiter and people expect the law to guarantee their interests, without bias, in a just form especially in democratic regimes and the law. According to Owasanoye, Akanle and Nguri (2010), rule of law must of necessity guarantee access of the marginalized groups to justice if there is to be seen that a nation or community is experiencing rule of law and is seriously in search and need of development.

Law at this level would then be seen as mechanisms for ensuring justice within the local and national interest, ensure freedom and capabilities, reduce individual interests, social parochialism and open impartiality and ultimately ensure public justice and development (Sen, 2010 emphasis added). Once the law fails to do this or perceived to have failed in this line, the people lose interests in contributing to national development and could even resort to antidevelopment activities as many resort to resignation. Development then becomes a jungle and an ocean without bulldozers and compass to navigate the way out. This is very crucial and practical. Once a nation neglects the important 50 percent of its human resources on the altar of discrimination, it has only traded its developmental potentialities and possibilities due to mindless 
sentimentalism. Sustainable development can only be achieved on objective and all inclusive participatory engagements of all irrespective of gender, and located within the legal domains and frameworks. The law must be en-gendered and its application must be culturally neutral in manners that protect the interest of all and empower them to be on their best to contribute to national development in positive terms.

Both men and women have equal capacities to drive growth and development in Nigeria and other places in the world irrespective of primordial socio-cultural and traditional considerations that are atavistic to sustainable development in the final analysis. In line with this, Owasanoye (2009) concludes that the nexus of rule of law and national development is core and critical and essentially positive and mutually reinforcing. In other words, there can never be gender equality without rule of law and there can never be rule of law without gender equality. Hence, there can never be development without the two and there can never be the two without development especially sustainable one. The relationships among gender equality, rule of law and development is therefore nearly cure-all and development melting-pot. This is why Carothers (2010) opined that the acceptance of supremacy of the law is everywhere and its relationship with developments being emphasized as the answer to a multitude of challenges. This is as against Un-rule of law and gender inequality that drive development further afield.

\section{National and Global Legal/Policy Environments of Gender Equality}

Nations and international community have put in place legal and policy frameworks to guarantee gender equality in nations and across the world. Separate from the national efforts at achieving gender equality in Nigeria, therefore, there are international policies and laws that are related to the issues being considered in this article. The most fundamental instrument in Nigeria is the grund norm: The 1999 Constitution of the Federal Republic of Nigeria which ordinarily gives equal rights to the two genders in the country, and protects the rights of women in principle. There is also the Child Rights Acts (CRA). The CRA was passed in 2003 in Nigeria and it protects the rights of children in the country and clearly stipulates the protection of the rights of children equally irrespective of gender and social status.

In the CRA, there is the provisions for freedom from discrimination on the grounds of belonging to a particular community or ethnic group, place of origin, sex, religion, the circumstances of birth, disability, deprivation or political opinion; and it is stated categorically that the dignity of the child shall be respected at all times. No Nigerian child must be discriminated against for whatever reason. Interestingly, many States in the country have domesticated the CRA, although some are in the process of doing so. As at last count in early 2011, of the 36 Nigerian States, 24 are reported to have passed this legislation. There is also the Gender Affirmative Actions (GAAs) advocacy. This is however not a law but advocacy and lobbying strategy through which Civil Society Organizations interested in political participation of women in Nigeria 
rally round to mobilize more women for political participation and engagements. Political parties and governments are parleyed and lobbied for greater involvement of women in political parties activities. The agenda of GAA is to have at least 35 percent of elective and appointment positions for women in every dispensation as a start with positive for greater demands in the future the immediate destination being 50-50.

The most current of such instruments internationally is the United Nations Millennium Development Goals (MDGs). Goal number three (3) is considered central to all the MDGs: as is to "Promote Gender Equality and Empower Women by 2015" latest. Whether this is achievable or not is a big question given that 2015 is around the corner. The Convention on the Elimination of All Forms of Discrimination against Women (CEDAW) is another very popular international instrument in this regard. CEDAW was adopted in 1979 by the United Nations General Assembly and acceded to by at least 180 nations. CEDAW sets down rights for women, of freedom from discrimination and equality under the law based on the realization that the rights and equality of women and men is key to the survival and development of children and to building healthy families, communities and nations. Another instrument is the United Nations Fourth World Conference on Women in Beijing (1995) which is the Beijing Platform of Action. There are also the Rio Conference on Environment and Development (1992), the Vienna Conference on Human Rights (1993), the Cairo Conference on Population and Development (1994), the Copenhagen World Summit for Social Development (1995), and the Istanbul Conference on Human Settlements (1996). There is also The Convention of the Rights of the Child (CRC) which has the same provisions as the CRA of Nigeria. In fact, the CRA is a domestication of the CRC which is the global and international instrument for child rights.

It is important to note that these instruments, both local and international, are to give legislative and legal frameworks for gender equality, advocacy and movements. This is to make gender discrimination justiceable and pragmatically purposeful. While these instruments are myriads, it could be observed that a strand of uniform purpose passes through all of them in manners that interconnect their purpose. They are all to ensure that gender equality protects the rights of the two genders. Based on observable trends in Nigeria, the question is: have these instruments been effective? Although gender equality movements now have legal regimes to serve as frameworks of actions, effectiveness of these instruments appear to be mostly on paper as the party and cocktail of gender discriminations seem to continue unabated in Nigeria and most sub-Saharan African countries. This shows that the drivers of gender discrimination are not easily amenable to law, are most of the time not justiceable, are more deep-seated and more fundamental than laws can address, at least in the short and medium terms. 


\section{Conclusion}

Gender issues are as fundamental, as old and as structural as humans. The history of humans is thus incomplete without exploration of gender relations and dynamics within developmental and legal-political contextualities and specificities. It is, in fact, impossible to consider development issues and trajectories without recourse to gender dynamics if that analysis is to be sufficiently robust and comprehensive. This is even more so relative to Nigeria as the nation transits governance domains and navigates development pathways with implications for justice and legal frameworks. Sociology should thus be more reflexive and engaging in handling issues that could interface to affect real and sustainable national development in Nigeria. Against the backdrop of Nigeria's democratization, therefore, gender issues must be given analytical priorities and must be interfaced with rule of law which gives institutionalization to human relationships in the nation.

Although it is possible to think that gender issues are obsolete research areas in Nigeria, that is erroneous and fallacious and such thoughts and beliefs must be jettisoned in their entirety. Gender equality issues must be put in research front burners most especially during this democratic consolidation of the country. This is because democratization is often seen as being synonymous with equality and fairness, and all genders will expect protection and justice if they are to positively contribute to national development. Democracy must thus of necessity provide and guarantee gender equality within appropriate legal frameworks in sustainable manner to prevent democratic implosion.

Attitude, behaviours and cultural practices are not ethereal and immutable. They are liable to change but with determined and concerted efforts. All hands must be on deck to achieve attitude, behaviour and practice change to achieve gender equality and workable rule of law that will transcend the political mantra for democratic governance legitimization in Nigeria to achieve needed sustainable development. Targeted interpersonal relations and increased media reporting that are positive will lead to needed change and quicken democratic institutionalization. They will change gender inequality and improve rule of law and development domains in Nigeria. Rule of law and gender equality for national development reporting in the country should therefore be seen as public good that will benefit all in the long run. It may not necessarily be seen as amenable to economic gains and capitalistic tendencies. Development will start with everyone at personal level and only crystallize at the community level. Everyone at all levels has a way of contributing to gender equality and selective application of the law once the issues of gender come to the fore unfortunately this negatively affect development and make democratization difficult.

As a new research frontier to be opened by this article, it must be noted that the gender imbalance and inequality systems are changing and manifesting in new ways that call for new methods of interrogation in gender inequality, rule of law and development. As efforts towards women empowerment over the years yield positive results, the pendulum of inequality is tilting against men, not surprisingly though. A careful consideration of the Nigerian social, economic, 
educational and political systems will reveal this. Consider carefully the socalled new generation banks, telecommunication/blue chips companies, higher institutions of learning and even international organizations. The point be made is that most of the companies that pay good salaries and allowance in Nigeria in contemporary terms now prefer and employ more women than men. More females are getting admissions to universities and other higher institutions (both public and private) and are graduating with better grades than boys, and are becoming more assertive and occupying more powerful and influential positions. There appears to be an increasing phenomenon of 'house husbands' and 'Daddy's day care.' Hence, more women are becoming bread winners in Nigerian urban homes than ever before. An objective and earthworm view of Nigerian social systems and processes could show some interesting dynamics heralding the end of orthodox patriarchy and traditional power systems and their consequences with huge implications for governance, social relations and development in the country.

Regardless of the practical and theoretical leaning, therefore, it is important for Sociologists to be very observant and assertive in monitoring and engaging developments relative to gender relations, equality, democratic manifestations and legal regimes in Nigeria to capture ensuing dynamics. Since the most constant thing in societies is change, changes will certainly arise but the nature and the direction of the change must be well captured for holistic and comprehensive as well as timely examination. Against this background, Sociologists must be watchful so as to be able to continue to contribute timely and useful knowledge to national development particularly relative to gender equality, rule of law and development in Nigeria now and in the future.

\section{References}

Azinge, E. (2009) Rule of Law, Due Process and Good Governance, in Azinge, E. and Owasanoye, B. ( eds.). Rule of Law and Good Governance. Nigeria: Nigerian Institute of Advance Legal Studies. Pp. 273-283.

Carothers, T. (2010) Rule of Law Temptations, in Heckman, J.J., Nelson, R.L. and Cabatingan, L. (eds.). Global Perspectives on the Rule of Law. London: Routledge. Pp. 17-27.

Federal Republic of Nigeria (2007) Official Gazette. 94. 24. Government Notice No. 21.Lagos. May 15th.

FMWA \& SD (Federal Ministry of Women Affairs and Women Development) (2007) National Gender Policy. FRN.

Ganguly-Scrase, R. (2003) Paradoxes of Globalization, Liberalization, and Gender Equality: The Worldviews of the Lower Middle Class in West Bengal, India. Gender and Society. 17 (4):544-566. 
Gray, A.M. and Neill, G. (2011) Creating a Shared Society in Northern Ireland: Why we Need to Focus on Gender Equality. Youth and Society. 43(2):468487.

Hamer, J. and Hamer, I. (1994) Impact of a Cash Economy on Complementary Gender Relations among the Sadāma of Ethiopia. Anthropological Quarterly. 67 (4):187-202.

Joireman, S.F. (2001) Inherited Legal Systems and Effective Rule of Law: Africa and the Colonial Legacy. The Journal of Modern African Studies. 39 (4):571-596.

Leve, L. (2007) 'Failed Development' and Rural Revolution in Nepal: Rethinking Subaltern Consciousness and Women's Empowerment. Anthropological Quarterly. 80 (1):127-172.

Melander, E. (2005) Political Gender Equality and State Human Rights Abuse. Journal of Peace Research. 42 (2):149-166.

Mika LaVaque-Manty, M. and Le Vaque-Manty (2006) Dueling for Equality: Masculine Honour and the Modern Politics of Dignity. Political Theory. 34(6):715-740.

Nyamu-Musembi, C. (2006) Ruling out Gender Equality? The Post-Cold War Rule of Law Agenda in Sub-Saharan Africa. Third World Quarterly. 27 (7). The Politics of Rights: Dilemmas for Feminist Praxis. Pp. 1193-1207.

Owasanoye, B. (2009) Rule of Law and National Development, in Azinge, E. and Owasanoye, B. (eds.). Rule of Law and Good Governance. Nigeria: Nigerian Institute of Advance Legal Studies. Pp. 254-271.

Owasanoye, B., Akanle, O. and Nguri, J. (2010) Rule of Law in Nigeria: Findings from a Pilot Study. Nigeria: Human Development Initiatives and Department for International Development (DfID), and British Council.

Platek, M. (2004) Hostages of Destiny: Gender Issues in Today's Poland. Feminist Review, 76:5-25. Post-Communism: Women's Lives inTransition

Risman, B.J. (2004) Gender as a Social Structure: Theory Wrestling with Activism. Gender and Society. 18 (4):429-450.

Rizzo, H., Abdel-Latif, A. and Meyer, K. (2007) The Relationship Between Gender Equality and Democracy: A Comparison of Arab Versus Non-Arab Muslim Societies. Sociology. 41(6):1151-1170.

Sen, A. (2010) Global Justice, in Heckman, J.J., Nelson, R.L. and Cabatingan, L. eds. Global Perspectives on the rule of law. London: Routledge, 55-70.

The World Bank (2003) Social Development Notes: Conflict Prevention \& Reconstruction. No.11 May.

UNICEF (United Nations Children Emergency Fund) (2005) UNICEF Information Sheet on Child Labour in Nigeria. Geneva: UNICEF

Von Braun, J. (2008) Rising World Food Prices: How to address the Problem. Bridges, May, 2008. Pp. 3-4.

World Development Report (2012) Gender Equality and Development. Washington DC: The World Bank.

Yumkella, K. (2008) Nigeria is off-track on MDGs. Nigerian Tribune, Tuesday, pp.22. 